\title{
Refining the concept of cultural competence: building on decades of progress
}

Rosalie D Thackrah BA, GradDipEd, MA PhD Candidate, 1 and Lecturer/Research Fellow ${ }^{2}$

Sandra C Thompson $\mathrm{MPH}, \mathrm{PhD}$, FAFPHM Director and Professo of Rural Health

1 Combined Universities Centre for Rural Health University of

Western Australia

Perth, WA.

2 Faculty of Health Sciences, Curtin University,

Perth, WA.

R.Thackrah@ curtin.edu.au
$T$ he impact of culture in the clinical encounter is recognised as a contributing factor to patterns of health service utilisation and is a key focus of cultural competence training. ${ }^{1,2}$ While some studies have identified beneficial effects of cultural competence on health professionals' knowledge, attitudes and skills, and on levels of patient satisfaction, few have explored its effects on health outcomes. This is unsurprising given that the factors affecting health outcomes are numerous and complex. The Commission on Social Determinants of Health has noted that health inequalities are largely related to the circumstances of people's lives and to the services available to treat illness. ${ }^{3}$ In turn, people's circumstances and the health care system are shaped by social, political and economic realities. Cultural knowledge is embedded in these circumstances and realities, and helps frame patients' explanatory models of illness and clinicians' decision making. ${ }^{2}$ It has been argued, however, that these two world views can collide in the clinical encounter. ${ }^{4}$ Cultural competence training aims to improve the quality of health care and reduce health disparities by focusing on communication and trust between patients and health care providers and enhancing provider knowledge about sociocultural factors linked to health beliefs, practices and utilisation of services. ${ }^{5}$

The idea of educating health professionals to be culturally competent began in earnest in the United States in the 1990s. The term "cultural competence" first emerged in the late 1980s and was defined as "a set of congruent behaviors, attitudes, and policies that come together in a system, agency or amongst professionals and enables that system, agency, or those professionals to work effectively in cross-cultural situations". ${ }^{6}$ Cultural competence in health care was described as an emerging field in the US in 2002; however, over the past decade it has become firmly embedded in professional accreditation standards. ${ }^{7}$ In Australia, health professional competencies consistently make reference to cultural competence, ${ }^{8,9}$ and the concept has received legitimacy with its incorporation into significant health policy documents. ${ }^{10-13}$

While strategies associated with cultural competence aim to make services more accessible for patients from diverse cultural backgrounds, more recently they have focused on specific groups, particularly Indigenous Australians, where the failure of services to address large disparities in health outcomes is stark and confronting. Connecting Indigenous patients with the health system and communicating effectively can be challenging and

\begin{abstract}
Summary
- Cultural competence strategies aim to make health services more accessible for patients from diverse cultural backgrounds. Recently, such strategies have focused on specific groups, and particularly Indigenous Australians, where services have failed to address large disparities in health outcomes.

- Limitations of cultural competence largely fall into three categories: lack of clarity around how the concept of culture is used in medicine, inadequate recognition of the "culture of medicine" and the scarcity of outcomesbased research that provides evidence of efficacy of cultural competence strategies.

- Narrow concepts of culture often conflate culture with race and ethnicity, failing to capture diversity within groups and thus reducing the effectiveness of cultural competence strategies. This also hampers the search for evidence linking cultural competence to a reduction in health disparities.

- Attention to cultural complexity, structural determinants of inequality and power differentials within health care settings not only provide a more expansive notion of cultural competence and a nuanced understanding of the role of culture in the clinic, but may assist in determining the contribution that cultural competence strategies can make to a reduction in health disparities.
\end{abstract}

has often not been done well (Box 1 and Box 2). Indigenous cultural competence has been identified as a desirable attribute of Australian health professionals. ${ }^{13-18}$ Perhaps as a result of the plethora of alternative concepts such as cultural safety, cultural awareness and sensitivity, cultural security and humility, and more recently cultural literacy, the use of an overarching term was inevitable, despite most concepts having different frames of reference. ${ }^{17,19}$ Cultural competence strategies usually target the health workforce with the aim of improving the interactions between the patient, the provider and the health care system, as the intermediate step to improving health care utilisation, service delivery and health outcomes. Many aspects of this concept remain the subject of debate.

\section{Social science perspectives}

Limitations of cultural competence highlighted by social scientists working in clinical and academic settings largely fall into three categories: lack of clarity around the concept of culture, inadequate recognition of the "culture of medi- 


\section{No wonder people don't come back*}

One of the Aboriginal doctors was doing a paeds [paediatrics] trip and a patient had been driven overnight from Wiluna. And the doctors barely had time to see them [the family] and then they did not make them welcome, so this Aboriginal doctor was horrified. No wonder people don't come back. It is the same with ordinary appointments. The reason why people miss appointments is because they can't see the value of them. And l'll ask them what happened at their outpatient appointment and they'll say "They did what you do". "What did they say?" "They said they will write you a letter". "Did they examine you?" "Not really". So there is a sense that these appointments are futile, especially the follow-up ones.

The young doctors that see the patients are afraid to discharge them from the clinic and so when they see them and everything is the same, they rebook them for another appointment for no good reason except they are too nervous to say "you don't need to come back".

It is a hassle to get a babysitter for your six kids, find transport, wait 4 hours... for nothing.

* Transcript notes from an interview with an experienced general practitioner who works at an Aboriginal Medical Service. The GP describes the lost time and opportunity costs for patients travelling great distances for appointments that may be very brief and perhaps not even necessary.

cine" and the scarcity of outcomes-based research that provides evidence of efficacy in improving health.

\section{Unpacking culture}

While it is recognised that a patient's cultural background may be significant in clinical encounters, lack of clarity about the concept of culture can distort its impact. 2,4,20-22 Anthropology, the discipline from which the term "culture" originated, offers many definitions but most make reference to a system of shared meanings or guidelines that are inherited and provide a lens through which to view the world. Contemporary anthropologists stress variations that exist across cultures with respect to beliefs, practices, norms, behaviours and expectations. Helman, for example, notes that culture is "an increasingly fluid concept, which in most societies is undergoing a constant process of change and adaptation" ${ }^{20}$ Social scientists stress that cultures are complex, heterogeneous and dynamic, and intricately connected to the social context of people's lives. $^{2,4,21,22}$

So how does this understanding of culture differ from its usage in medical settings? Critiques from social scientists suggest that culture is often conflated with race and ethnicity, resulting in reification of existing racial categories. ${ }^{4}$ Central to this criticism is the failure to recognise diversity within cultures and the concomitant reductionism whereby culture is identified as a variable associated with essential differences between groups. Culture is viewed as a "risk factor" and cultural attributes as potential sources of the problem. Kirmayer noted that culture has been framed in terms of "ethnoracial blocs" which "conflate language, geographic origin, ethnicity and race" and "do not capture the diversity of society and the rapidly growing numbers of people who define themselves in hybrid ways that cut across these categories or escape them entirely". ${ }^{21}$ Cultural competence literature tends to associate culture with group membership and shared beliefs and values that influence behaviour in health care settings. ${ }^{21}$ Not only does this approach underestimate cultural diversity within groups, but the process of "essen- tialising" culture removes individuals from their complex social worlds in which the structural and material determinants of inequality may be as powerful as cultural influences on health inequity. In an attempt to provide more conceptual clarity around cultural competence, Lo and Stacey coined the term "hybrid habitus" which interprets patients' cultures as "the broad, less than fully conscious cultural orientations that shape a patient's sense-making in clinical settings... [and] in turn, are shaped by surrounding, intersecting structural forces". ${ }^{22}$ These forces may include socioeconomic status, gender, language and experiences of racism, all of which can interact with cultural orientations and influence the clinical encounter. This deeper understanding of culture in all its complexity has practical implications in health care settings. A patient's culture is not reduced to stereotypical attributes, but rather understood as comprising layers of meaning that extend beyond values, beliefs and practices and are shaped by and in turn shape social structures.

However, any examination of the meaning and use of "culture" needs to consider the culture of medicine itself to assess its role in reproducing or addressing health inequities.

\section{Culture of medicine}

In the US, Good and colleagues questioned why disparities in health care continue to exist despite the introduction of cultural competence training in health professional programs. ${ }^{23}$ They suggested the need for a critical analysis of the culture of medicine where the "social processes within our complex medical institutions" are explored, including the presence of institutional racism, power imbalances and the role of professional socialisation. Taylor reinforces this, noting that cultural competence strategies have an overemphasis on the patient's culture with scant attention paid to the culture of biomedicine. ${ }^{24}$ Institutional and professional medical culture is characterised by expert language and efficiency in clinical decision making based on legitimate medical knowledge. Taylor suggests that "it is confidence in the truth of medical knowledge that underwrites physicians' special power to alleviate suffering". Medical knowledge is thus not seen as a cultural product but as "real" knowledge which leads her to describe medicine as "perceiving itself to be a 'culture of no culture' ". ${ }^{24}$ While some may disagree with this, it has consequences for the development of cultural competence curricula that "go beyond focusing on 'other' cultural groups, and attend to cultural dimensions of medicine itself". Central to this discussion is the potential mismatch between professional medical socialisation, institutional practices and cultural competence strategies. Indeed, clinicians sometimes can be at odds with institutional directives and feel constrained by administrative practices that may compromise patient care.

Despite cultural competence training becoming commonplace in medical programs in Australia and elsewhere, few studies have focused on the culture of medicine itself. As Good et al note "rarely do students have the time or the formal sanction to critically analyze the profession and institutions of care to examine how treatment choices, quality of care and research practices are shaped; or how medical culture may produce processes that evolve into 


\section{The heart of the matter*}

Another thing is patients are not told enough; it's a bit of a paternalistic attitude that doctors have anyway, and even more so with Aboriginal patients, they are not given enough information. One story is of a patient who told me he loved this private cardiologist and I was amazed. I couldn't understand why, because this guy was as rough as guts and the doctor was a posh threepiece suit sort of guy... When I asked him he said because the doctor had a fabulous model of a heart and he shows me everything, you know. He just thought that guy was the bee's knees... he took the time to show him pictures of his arteries. so taking the time to show people with models and trying to explain what you're doing is just fundamental. .

Of course it's hard in hospitals because doctors have so little time; but if they don't explain things properly and patients don't take their tablets because things aren't clearly explained then they are wasting their time anyway.

* Transcript notes from an interview with an experienced general practitioner who works at an Aboriginal Medical Service. This excerpt highlights good communication and its importance in breaking down barriers between patient and clinician. tended to be in a positive direction. ${ }^{28}$ However, the authors identified many methodological limitations of existing studies and drew attention to the overall paucity of highquality research, concluding that the evidence was not robust. Looking ahead, they noted that "subjective constructs such as patient trust and the quality of the patient experience using validated measures have emerged as outcomes of intrinsic value that should also be considered in the cause-effect dynamic". ${ }^{28}$ Inherent in cultural competence measurement issues is the question of who decides whether a health professional has achieved cultural competence; arguably, the patient as the recipient of services is best positioned to make this judgement. The authors noted that because educational interventions are often removed from clinical outcomes, other measures such as enhanced trust between patient and practitioner and a high degree of satisfaction with a clinical encounter are worthy outcomes in health care settings and may also contribute to improved levels of utilisation. ${ }^{28}$

institutional racism ... in clinical practice" ${ }^{23}$ Kleinman and Benson go further, suggesting that the culture of biomedicine is "key to the transmission of stigma, the incorporation and maintenance of racial bias in institutions, and the development of health disparities across minority groups". ${ }^{2}$ Implementing a more expansive notion of cultural competence that incorporates greater critical analysis of biomedicine has potential for less discordance between institutional culture and strategies aimed to improve culturally informed care.

\section{Problems of measurement and limited outcomes- based research}

Finally, critiques of cultural competence by social scientists and others have drawn attention to inadequate measures of the concept and the scarcity of outcomes-based research that links cultural competence strategies to better health. ${ }^{25-30}$ A study of quantitative measures of cultural competence found many hidden assumptions in survey questions designed to assess the impact of educational interventions, including the notion that frequent contact or immersion experiences necessarily enhance competence. ${ }^{29}$ Much depends on the kinds of interactions and the quality of the experiences, with contact alone not necessarily fostering insight. Recent studies also have found a lack of rigorous evaluation of cultural competence measurement tools, with few instruments having been validated. Chun noted that cultural competence training is often viewed as "unscientific" due to inadequate measurement techniques that can undermine implementation efforts. ${ }^{27}$ This is reinforced by findings of a review of the methodological rigour of studies evaluating cultural competence, which found a consistent lack of rigour, the consequence of which "limits the evidence for the impact of cultural competence training on minority health care quality" ${ }^{26}$ In addition to rigorous instrument evaluation, qualitative methods, including observations, interviews and reflective journals should supplement traditional survey techniques when determining the effectiveness of cultural competence training. ${ }^{29}$

The first systematic review of studies assessing whether educational interventions to improve cultural competence were linked to improvements in health outcomes concluded that where an association was established, it

\section{Conclusion}

Social science critiques of cultural competence highlight the lack of conceptual clarity around the use of the term "culture" in clinical encounters, inadequate recognition of the "culture of medicine" and a scarcity of outcomes-based research that provides evidence of efficacy in improving health.

The value of training in cultural competence as an educational intervention will ultimately be validated by enhancing access to and achieving equity of health services and better health outcomes for culturally diverse groups. Given strong evidence that inequities in health arise from inequities in society, cultural competence strategies should not be divorced from addressing the material circumstances of people's lives, an issue pertinent to the oldest and newest inhabitants of Australia. Perhaps there are unrealistic expectations about what culturally informed health care delivery can achieve in the absence of systematic attention to the structural and financial impediments to implementing the professional advice provided in health encounters. A nuanced and sophisticated understanding of "culture" in clinical settings would be a useful start to discerning the role that cultural competence plays in reducing health disparities in minority groups.

Acknowledgements: We acknowledge support through an NHMRC Capacity Building Grant (533547; Building Mental Wealth: improving mental health for better health outcomes among Indigenous Australians), administered by Curtin University. The Health and Ageing.

Competing interests: No relevant disclosures.

Provenance: Not commissioned; externally peer reviewed.

1 Betancourt JR. Cross-cultural medical education: conceptual approaches and frameworks for evaluation. Acad Med 2003; 78: 560-569.

2 Kleinman A, Benson P. Anthropology in the clinic: the problem of cultural competency and how to fix it. PLoS Med 2006; 3: e294.

3 Commission on Social Determinants of Health. Closing the gap in a generation: health equity through action on the social determinants of health. Geneva: World Health Organization, 2008. http://www.who.int/social_determinants/ thecommission/finalreport/en/index.html (accessed Apr 2013).

4 Carpenter-Song EA, Nordquest Schwallie M, Longhofer J. Cultural competence reexamined: critique and directions for the future. Psychiatr Serv 2007; 58 : $1362-1365$.

5 Betancourt J, Green A, Carrillo J, Ananeh-Firempong 0 2nd. Defining cultural competence: a practical framework for addressing racial/ethnic disparities in health and health care. Public Health Rep 2003; 118: 293-302. Combined Universities Centre for Rural Health receives funding from the Department of 
6 Cross TL, Bazron BJ, Dennis KW, Isaacs MR. Towards a culturally competent system of care. Volume 1. A monograph on effective services for minority children who are severely emotionally disturbed. Washington DC: Georgetown University Child Development Centre, 1989.

7 Betancourt JR, Green AR, Carrillo JE. Cultural competence in health care: emerging frameworks and practical approaches. http://www. commonwealthfund.org/Publications/Fund-Reports/2002/Oct/CulturalCompetence-in-Health-Care--Emerging-Frameworks-and-PracticalApproaches.aspx (accessed Jun 2013).

8 Australian Medical Council. Accreditation standards for primary medical education providers and their program of study and graduate outcome statements. http://www.amc.org.au/images/Accreditation/FINALStandards-and-Graduate-Outcome-Statements-20-December-2012.pdf (accessed Apr 2013).

9 Nursing and Midwifery Board of Australia. National competency standards for the midwife. Canberra: Australian Nursing and Midwifery Council, 2006. http://www.nursingmidwiferyboard.gov.au/Codes-Guidelines-Statements/ Codes-Guidelines.aspx (accessed Mar 2013).

10 Australian Health Ministers' Advisory Council Standing Committee on Aboriginal and Torres Strait Islander Health Working Party. Cultural respect framework for Aboriginal and Torres Strait Islander health, 2004 - 2009. Adelaide: Department of Health South Australia, 2004. http://www.sapo.org. au/pub/pub2142.html (accessed Mar 2013).

11 Ethnic Communities' Council of Victoria. Cultural Competence: guidelines and protocols. Melbourne: ECCV, 2006. http://eccv.org.au/library/doc/Cultural CompetenceGuidelinesandProtocols.pdf (accessed Mar 2013).

12 National Health and Medical Research Council. Cultural competency in health: a guide for policy, partnerships and participation. Canberra: NHMRC, 2005. http://www.nhmrc.gov.au/guidelines/publications/hp19-hp26 (accessed Mar 2013).

13 Universities Australia. Guiding principles for developing Indigenous cultural competency in Australian universities. Canberra: Universities Australia, 2011. http://www.universitiesaustralia.edu.au/lightbox/1313 (accessed Mar 2013).

14 Adams K. Indigenous cultural competence in nursing and midwifery practice. Aust Nurs J 2010; 17: 35-38.

15 Downing R, Kowal E. Putting Indigenous cultural training into nursing practice. Contemp Nurse 2010; 37: 10-20.
16 Farrelly T, Lumby B. A Best practice approach to cultural competence training. Aborig Isl Health Work J 2009; 33: 14-22.

17 Thomson N. Cultural respect and related concepts: a brief summary of the literature. Aust Indigenous HealthBulletin 2005; 5: 1-11.

18 Victorian Aboriginal Child Care Agency. Aboriginal cultural competence framework. Melbourne: Department of Human Services, 2008. http://www. dhs.vic.gov.au/_data/assets/pdf_file/0011/580934/Aboriginal_cultural_ competence_2008.pdf (accessed Mar 2013).

19 Ewen SC. Cultural literacy and Indigenous health in medical education. Focus Health Prof Educ 2011; 13: 68-74.

20 Helman CG. Culture, health and Illness. 5th ed. London: Hodder Arnold, 2007.

21 Kirmayer LJ. Rethinking cultural competence. Transcult Psychiatry 2012; 49 : 149-164.

22 Lo M-C, Stacey CL. Beyond cultural competency: Bourdieu, patients and clinical encounters. Sociol Health Illn 2008; 30: 741-755.

23 Good M-JD, James C, Good BJ, Becker AE. The culture of medicine and racial, ethnic, and class disparities in healthcare. In: Smedley BD, Stith AY, Nelson AR, editors. Unequal treatment: confronting racial and ethnic disparities in healthcare. Washington DC: National Academies Press, 2003.

24 Taylor JS. Confronting "culture" in medicine's "culture of no culture". Acad Med 2003; 78: 555-559.

25 Beach MC, Price EG, Gary T, et al. Cultural competency: a systematic review of health care provider educational interventions. Med Care 2005; 43: 356-373.

26 Price EG, Beach MC, Gary TL, et al. A systematic review of the methodological rigor of studies evaluating cultural competence training of health professionals. Acad Med 2005; 80: 578-586.

27 Chun MB. Pitfalls to avoid when introducing a cultural competency training initiative. Med Educ 2010; 44: 613-620.

28 Lie DA, Lee-Rey E, Gomez A, et al. Does cultural competency training of health professionals improve patient outcomes? A systematic review and proposed algorithm for future research. J Gen Intern Med 2011; 26: 317-325.

29 Kuma-Tan Z, Beagan B, Loppie C, et al. Measures of cultural competence: examining hidden assumptions. Acad Med 2007; 82: 548-557.

30 Brach C, Fraserirector I. Can cultural competency reduce racial and ethnic health disparities? A review and conceptual model. Med Care Res Rev 2000; 57 Suppl 1: 181-217. 